\title{
Educação para compatibilizar desenvolvimento e sustentabilidade
}

\section{Education to achieve sustainability-oriented development}

\author{
Ubiratan D'AMBROSIO*
}

\begin{abstract}
RESUMO
Promover uma Educação adequada para que a sociedade possa buscar e consolidar o desenvolvimento voltado para a sustentabilidade, no mais amplo sentido, é, sem dúvida, uma questão essencialmente política. Mas é, sobretudo, uma questão que leva às perguntas: com que freqüência, com qual atitude, com quais pesquisas e ações, a academia pode sugerir caminhos neste sentido? Este artigo demonstra que a resposta depende de um reconhecimento da relação entre os sistemas de conhecimento e os valores humanos. De forma geral, pode-se afirmar que este tipo de educação voltada para pensar, conjuntamente, valores éticos e saberes transdisciplinares é, no fundo, o que poderia ser nominado de Educação para a Paz, ou seja, uma conduta que pode conduzir o ser humano a atingir o estado de real consciência, só possível quando conhecimento e comportamento humano estejam solidários.
\end{abstract}

Palavras-chave: educação; desenvolvimento e sustentabilidade; valores éticos; transdisciplinaridade e complexidade.

\begin{abstract}
Promoting proper Education so that society can seek and achieve sustainability-oriented development, in the broadest sense, is without any doubt an essentially political matter. It is, above all, a topic that leads to the following questions: how frequently, with which attitude, with which research and actions, can Academia suggest ways to that end? This article shows that the answer depends on recognizing the relationship between knowledge systems and human values. In general terms, one can say that this kind of Education, aiming to think ethical values and transdisciplinary knowledge at the same time, is ultimately what could be called Education for Peace - that is to say, a path leading the human being to a state of real conscience, only possible when both human knowledge and behavior are solidary.

Key words: education; development and sustainability; ethical values; transdisciplinarity and complexity.
\end{abstract}

\footnotetext{
Professor Emérito de Matemática da Universidade Estadual de Campinas / UNICAMP. Atualmente, professor do Programa de Estudos Pós-Graduados de História da Ciência da Pontifícia Universidade Católica de São Paulo / PUC; professor credenciado no Programa de Pós-Graduação da Faculdade de Educação da Universidade de São Paulo; professor do Programa de Pós-Graduação em Educação Matemática do Instituto de Geociências e Ciências Exatas da Universidade Estadual Paulista "Julio de Mesquita Filho" / UNESP; professor visitante no Programa Sênior da FURB / Universidade Regional de Blumenau. Contato: ubi@usp.br.
} 
Promover uma educação adequada para que a sociedade possa buscar e consolidar o desenvolvimento voltado para a sustentabilidade, no mais amplo sentido, é, sem dúvida, uma questão essencialmente política. Mas pergunta-se, com freqüência, que atitude, que pesquisa e que ação a academia pode sugerir? Acredito que a resposta depende de um reconhecimento da relação entre sistemas de conhecimento e valores humanos.

Desenvolvimento e sustentabilidade dependem do relacionamento do homem com a natureza, que é, necessariamente, uma relação de conflito. Desde o início esclareço que utilizo a palavra conflito como algo inerente à diversidade e à diferença entre indivíduos que coexistem. Há diferentes necessidades, diferentes interesses, diferentes expectativas. Por extensão, usam-se as expressões conflitos interiores ou intrapsíquico na psicanálise.

A mesma realidade, que é constituída de fatos e fenômenos, incluindo mitos, misticidade e mitistória, informa diferentemente indivíduos diferentes, provocando estímulos e reações diferentes, da qual resultam ações, em geral conflitantes, muitas vezes mutuamente excludentes. Como exemplo, a realidade visível dá, a um determinado indivíduo, informações que dependem da sua acuidade visual.

Entendemos natureza no sentido amplo, a Terra e todos os demais corpos celestes, ar e águas, solo e minerais, todas as espécies vivas. $\mathrm{O}$ fenômeno vida pode ser explicado como a essencialidade mútua desses três elementos. Cada elemento provê, para os outros, o que é essencial para a sustentabilidade de todas as espécies vivas, em particular do homem. Há, obviamente, uma relação de conflito. Respirar significa inalar ar com certas propriedades químicas e exalar ar com propriedades diversas. O mesmo se dá com a água. Para se alimentar, elimina-se uma vida e devolve-se, à natureza, dejetos. O processamento físico-químico, pelo corpo, de substâncias ingeridas, que ocorre nas células, tecidos, órgãos e sistemas dos seres vivos, é a essência da vida. O encontro com o outro da mesma espécie, mas com características individuais necessariamente distintas - macho e fêmea - é o que garante a continuidade da espécie. A existência e a essencialidade do outro diferente são absolutamente necessárias para a continuidade de uma espécie. Numa mesma espécie, indivíduos dependem e devem conviver com outro diferente. Individualidade e alteridade devem necessariamente conviver, embora tendo reações conflituosas, como discutido acima. A convivência de diferentes, e mesmo a sobrevivência das espécies, depende da resolução de conflitos.

\section{Uma conceituação de paz}

Defino PAZ como o estado que resulta de ter resolvido os conflitos inerentes à diversidade.

A problemática da PAZ deve ser o centro de nossas reflexões. Violações da paz não se resumem em confrontos militares, que são as guerras. Na verdade, a paz é um conceito pluridimensional. Nosso objetivo deve ser atingir um estado de PAZ TOTAL, sem o que o futuro da humanidade estará comprometido.

Por PAZ TOTAL entendo a paz nas suas várias dimensões:

- PAZ INTERIOR - estar em paz consigo mesmo;

- PAZ SOCIAL - estar em paz com os outros;

- PAZAMBIENTAL - estar em paz com as demais espécies e com a natureza em geral;

- PAZ MilitaR - a ausência de confronto armado.

Paz não é apenas a inexistência de divergências e conflitos. As diferenças e, conseqüentemente, as divergências e conflitos, são parte da diversidade que caracteriza todas as espécies, e são, portanto, intrínsecas ao fenômeno vida. Cada indivíduo é diferente do outro. A busca de homogeneização da espécie humana é algo que contraria frontalmente as leis biológicas, pois teria, como resultado, a anulação da vontade individual. Em outros termos, a homogeneização causaria a subordinação e mesmo eliminação da consciência individual e a eliminação dos traços culturais. ${ }^{1}$ A homogeneização da espécie, tentada em inúmeros momentos da história, é hoje uma ameaça efetiva, em vista das possibilidades atuais de manipulação genética. Uma primeira aproximação dessa manipulação, ainda na era pré-DNA, é a conversão religiosa e social. ${ }^{2}$

Ver D’AMBROSIO, Ubiratan: A era da consciência. São Paulo: Editora Fundação Peirópolis, 1997.

A conversão religiosa pela catequese, sobretudo na conquista das Américas, é notória. A conversão social foi muito bem ilustrada numa novela de Anthony Burgess, A clockwork orange, de 1962. O livro deu origem, em 1971, a um filme de mesmo nome, dirigido por Stanley Kubrick. Ambos são disponíveis em tradução como A laranja mecânica. 
A existência de diferenças é natural e o encontro com o diferente é, em todas as espécies vivas, essencial para a continuidade da espécie. Mas é incrível como, num curto tempo de sua presença neste planeta, a espécie humana tornou esse encontro um ato sujeito à arrogância, à inveja, à prepotência, à ganância e à agressividade. A ética tem como objetivo transcender esse comportamento.

\section{Uma reflexão sobre o comportamento humano}

Uma reflexão sobre a paz pressupõe um enfoque teórico. Teorias resultam da escolha de categorias de análise. Para abordar a problemática da paz, trabalho com categorias que permitem entender a natureza humana e o fenômeno conhecimento, que é característico da nossa espécie. Nenhuma outra espécie animal revela conhecimento com as características da humana.

Devemos entender primeiramente o que é vida e como o ser humano se comporta como uma espécie diferenciada.

Minha visão de homem repousa sobre a análise das seguintes categorias:

- COSMOS

- PLANETA

- VIDA, COMO A RESOLUÇÃO DAS RELAÇÕES ENTRE CADA INDIVÍDUO, OUTRO(s) e A NATUREZA

- SOBREVIVÊNCIA DO INDIVÍDUO E DA ESPÉCIE

- HOMEM, COMO UMA ESPÉCIE DIFERENCIADA

- TRANSCENDÊNCIA

- INTERMEDIAÇÕES, CRIADAS PELO HOMEM, ENTRE INDIVÍDUO, OUTRO(s) e NATUREZA.

- comUNicAÇÃo

- COMPORTAMENTO

- CONHECIMENTO

- CONSCIÊNCIA e ÉTICA

$O$ problema fundamental é entender a relação entre o indivíduo e o seu comportamento, isto é, entre O SER HUMANO [substantivo] S SER HUMANO [verbo].
Ao longo da sua curta história, o homem tem procurado explicações sobre:

- quem é - e tem se acreditado o favorito de algum deus;

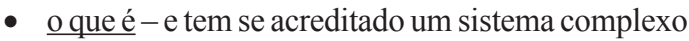
de músculos, ossos, nervos e humores;

- como é - e tem se acreditado uma anatomia com vontade;

- quanto pode - e tem se acreditado sem limitações à sua vontade e ambição.

Procurando entender quem é, o que é, e como é, o homem constrói sistemas de explicações que se organizam como história, religião, ciência, arte. E na explicação do quanto pode, concebe o poder. Essas explicações determinam a construção de modos de comportamento e de conhecimento.

Temos avançado muito no conhecimento do ser humano. Mas a grande angústia existencial resulta de não se encontrar uma resposta satisfatória à questão maior "por que sou?". Na verdade, nem mesmo se propõe essa questão. Mas, é ela que dá razão à nossa existência e é, igualmente,

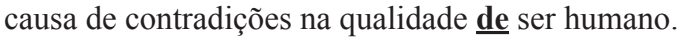

As violações da dignidade humana na civilização moderna, que chegam até a exclusão e mesmo eliminação de indivíduos, levam alguns a duvidarem da viabilidade de uma sociedade eqüitativa. A agressividade desmesurada contra a natureza põe em risco a continuidade da espécie.

As distorções da maneira como o homem tem se acreditado induziram poder, prepotência, ganância, inveja, avareza, arrogância, indiferença. Neste trabalho vou refletir sobre esse comportamento através do exame do conhecimento

$\mathrm{O}$ conhecimento tem sido utilizado para justificar nossas ações, muitas vezes desencorajando críticas e dando um caráter de verdade absoluta a crenças. Isso é particularmente notado no pensamento ocidental, fragmentado em disciplinas.

O grande pensador Sri Aurobindo (1872-1950) escreveu, numa das mais interessantes apreciações da cultura ocidental: 
Para a filosofia ocidental uma crença intelectual fixa é a parte mais importante de um culto, é a essência de seu significado e o que o distingue dos outros. Assim as crenças formuladas fazem verdadeira ou falsa uma religião [uma teoria, uma filosofia, uma ciência], de acordo com sua concordância ou não com o credo de seus críticos. ${ }^{3}$

O comportamento e o conhecimento constroem-se sobre crenças intelectuais basilares, geralmente chamadas paradigmas. Comportar-se e conhecer são identificados com o fazer e o saber. Na filosofia ocidental, que culmina com a chamada filosofia moderna, fazer e saber são tratados como ações distintas. O fazer está associado ao material, ao corpo, ao manual e, nas relações de trabalho, ao colarinho azul. O saber está associado ao espiritual, à mente, ao intelectual, ao colarinho branco.

As conseqüências dessa dicotomia e a valorização do saber sobre o fazer são evidentes na organização da sociedade moderna, na economia e na própria burocracia. ${ }^{4}$ Todo um processo de exclusão e de hierarquização está ancorado nessa dicotomia. Quem sabe manda e o fazer é interpretado como um ato de obediência.

\section{$A$ vida como uma tríade}

O fenômeno vida é inconcluso e complexo, em permanente transformação, sujeito a uma dinâmica da qual ainda sabemos pouco.

Identifico três fatos fundamentais para que a vida se realize, que são o indivíduo, o outro indivíduo (e por extensão outros indivíduos, isto é a sociedade) e a natureza, e as relações entre esses três fatos. Assim, a vida depende de seis elementos. A ausência ou a interrupção de qualquer desses seis elementos resulta no extermínio da vida. Metaforicamente, é como um triângulo, cuja existência é determinada por três vértices e três lados. Usando essa metáfora, chamo esse o TRIÂNGULO PRIMORDIAL. Graficamente,

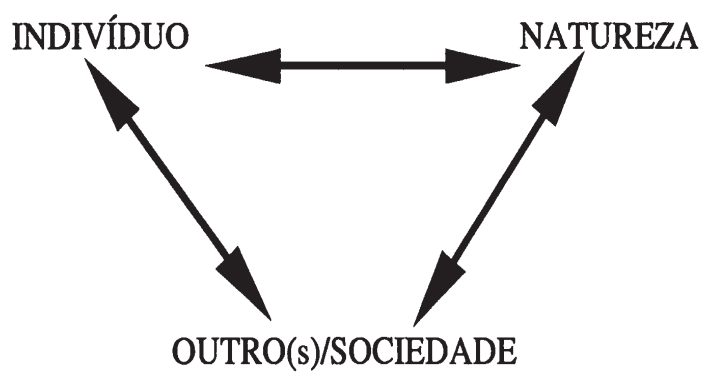

[subentende-se indivíduo e outro como sendo da mesma espécie e natureza como a totalidade planetária e cósmica]

Os três componentes, o INDIVÍDUO, o OUTRO e a NATUREZA, são mutuamente essenciais. Vida significa a resolução desse triângulo indissolúvel. Nenhum dos três componentes tem qualquer significado sem os demais.

O indivíduo é um organismo vivo, complexo na sua definição e no funcionamento de seu corpo, que age em coordenação com o cérebro, órgão responsável pela organização e execução de suas ações. Um corpo e um cérebro mutuamente essenciais, uma só entidade.

Os diferentes órgãos de um indivíduo interagem para manter o organismo vivo. Mas essa interação não pode se limitar ao organismo. Na verdade, a interação não pode ser no organismo, mas na tríade indivíduo/outro/natureza. Essa interdependência mútua é que deve servir de fundamento para entender a vida e o comportamento dos seres vivos.

Em todas as espécies, na busca de sobrevivência, o indivíduo se sujeita a comportamentos vitais básicos [meios]:

- reconhece o outro,

- aprende,

- é ensinado,

- adapta-se

- e cruza

com os objetivos [fins] de sobreviver e de dar continuidade à espécie. 
Uma questão maior, ainda não respondida, é "Quais as forças que levam os seres vivos a esses comportamentos vitais?"5

O homem, como todo organismo vivo, é complexo na sua definição e no seu funcionamento, e está sujeito aos mesmos comportamentos vitais básicos de todo ser vivo. Busca sobrevivência. A sobrevivência depende da resolução do triângulo da vida, que se dá no momento e no local. É uma ação no presente espacial e temporal. Espaço e tempo significam o aqui e o agora.

Mas, diferentemente dos demais seres vivos e mesmo das espécies mais próximas, o homem busca algo além da sobrevivência. Algumas vezes até rejeita sua sobrevivência. ${ }^{6}$

Esse algo mais é a superação do presente, estendendo sua percepção de espaço e de tempo para além do presente e do visível. O homem incursiona no passado e no futuro. Indaga sobre o que e como foi, e sobre o que e como será. Procura explicações sobre o passado e predições sobre o futuro, transcendendo espaço e tempo, criando representações sobre o que não vê.

A busca desse algo mais leva a indagar sobre o fenômeno vida, para o que é necessário conhecer o cosmos e o nosso habitat - o planeta Terra. O cosmos tem sido uma das grandes indagações do ser humano. Explicar o cosmos tem sido uma das primeiras motivações para construir sistemas de conhecimento. Inserido no cosmos está o nosso planeta, a Terra. Tem havido muito progresso nas explicações sobre o cosmos e o planeta Terra, e conseqüentemente sobre o fenômeno vida, sempre revelando incertezas e contradições.

\section{As intermediações criadas pela espécie humana}

Onde se situa a diferença de comportamento entre a espécie humana e as demais espécies?

O comportamento humano resulta de dois grandes pulsões:
1. sobrevivência, do indivíduo e da espécie, comum a toda espécie viva, já discutido acima e que se situa na dimensão do momento;

2. transcendência do espaço e do tempo, exclusividade da espécie humana, e que se situa numa outra dimensão, levando o homem a indagar "por quê?", "como?", "onde?", "quando?".

Sobrevivência e transcendência guardam uma relação simbiótica e distinguem o ser humano das demais espécies. Na resposta aos pulsões de sobrevivência e de transcendência surgem intermediações nas relações essenciais do indivíduo com a natureza e com o(s) outro(s) e o homem incursiona no passado, buscando explicações, e no futuro, buscando predições. Nesse incursionar gera conhecimento, que é reconhecido nas habilidades, nas técnicas, nos mitos e nas artes, nas religiões e nas ciências.

A diferença essencial entre a espécie humana e as demais espécies é o fato de termos criado, ao longo da nossa evolução, instrumentos, comunicação, principalmente a linguagem, e um sistema de produção, que servem de intermediações para a resolução do triângulo da vida:

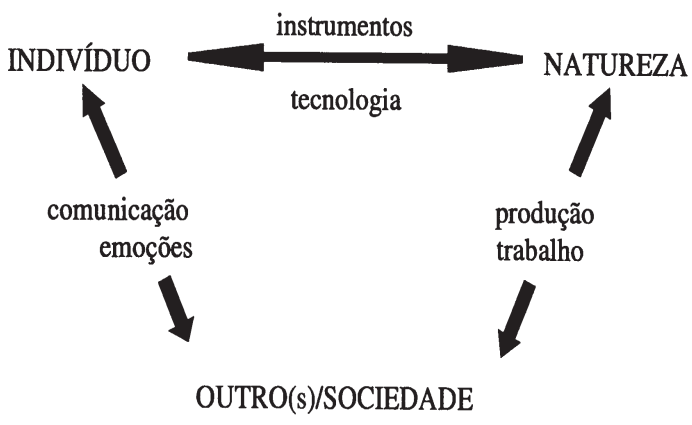

Criar e utilizar essas intermediações são possíveis graças ao encontro de comportamento e conhecimento. A percepção dos acertos e equívocos desse encontro é o que chamo consciência. ${ }^{7}$

\footnotetext{
5 No seu excelente livro, já clássico, MATURANA, Humberto Maturana e VARELA, Francisco. A árvore do conhecimento. As bases biológicas da compreensão humana. São Paulo: Palas Athena, 2001, introduzem o conceito de autopoiesis para explicar como um organismo se mantém vivo.

${ }^{6}$ A espécie humana é a única a praticar suicídio. Há uma forma de suicídio de células cancerosas e mesmo a prática individual do suicídio em algumas espécies, mas obedecendo a mecanismos fisiológicos. Suicídio sem o objetivo maior de dar continuidade à espécie é conhecido somente na nossa espécie.

$7 \quad$ Ver a obra citada na Nota 1 .
} 
No encontro com o outro, que também está em busca de sobrevivência e de transcendência, desenvolvese a comunicação.

\section{Valores}

O comportamento de cada indivíduo é aceito pelos seus próximos quando subordinados a parâmetros, que denominamos valores, e que determinam os acertos e equívocos na produção e utilização das intermediações criadas pelo homem para sua sobrevivência e transcendência.

Valores, assim conceituados, relacionam os meios com os fins. Os fins constituem as grandes utopias de indivíduos e de sociedades, dos sistemas de explicações e dos mitos, da cultura. Os meios dependem dos instrumentos materiais e intelectuais de que dispomos, também dependentes da cultura. Assim, os valores são manifestações culturais.

Uma excursão pela história revela que novos meios de sobrevivência e de transcendência fazem com que valores mudem. Mas, alguns valores permanecem:

- respeito pelo outro [diferente],

- solidariedade com o outro,

- cooperação com o outro.

Esses valores constituem uma ética maior, sem a qual a qualidade de ser humano se dilui.

Mas por que a humanidade caminha em direção contrária a essa ética, sem a qual

\section{a espécie humana não pode sobreviver?}

Essa questão maior tem sido a motivação dos grandes modelos filosóficos, religiosos e científicos.

Os modelos filosóficos, religiosos, científicos propõem "verdades" que têm sido aceitas como absolutas e que constituem sistemas de valores que guiam o comportamento humano. Os valores mudam, subordinados ao que prevalece nos sistemas sociais e econômicos.

Em muitas sociedades, a prioridade passa a ser a defesa do sistema de valores. A questão fundamental, que é a busca de sobrevivência associada à transcendência, passa a ser subordinada à defesa do sistema de valores [fundamentalismos]. É oportuno lembrar a citação de Aurobindo no início deste trabalho.

$\mathrm{Na}$ cultura ocidental, os sistemas de valores, da mesma maneira que as ciências e as religiões, são vistos como saberes concluídos, que têm uma arrogância intrínseca à própria concepção do concluído.

O conhecimento disciplinar, e conseqüentemente a educação, tem priorizado a defesa de saberes concluídos, inibindo a criação de novos saberes e determinando um comportamento social a eles subordinado. ${ }^{8}$

O conhecimento disciplinar evoluiu para a multidisciplinaridade, que é praticada nas escolas tradicionais, e para a interdisciplinaridade, ainda difícil de ser conseguida. Mas o verdadeiro avanço, abrindo novas possibilidades para o conhecimento, é a transdisciplinaridade. ${ }^{9}$

A transdisciplinaridade, assumindo a inconclusividade do ser humano, rejeita a arrogância do saber concluído e das certezas convencionadas e propõe a humildade da busca permanente.

O comportamento humano responde aos pulsões de sobrevivência e de transcendência, que estão intimamente ligados. Vai além de comportamento orientado pelo cérebro. Existe algo mais: a mente, que tem intrigado os filósofos desde a antiguidade, e a consciência, igualmente intrigante.

Onde se situam mente e consciência? No cérebro, que vem sendo tão bem estudado pelos neurologistas? $\mathrm{Ou}$ no que se costuma chamar inteligência, hoje bem estudada, inclusive no âmbito de uma disciplina que curiosamente se denomina inteligência artificial? E o que é inteligência? ${ }^{10}$

\footnotetext{
Particularmente prejudicial para a evolução da humanidade tem sido a maneira como o estabelecimento, o poder, expropriou as religiões derivadas do judaísmo e a ciência que delas resultou e criou mecanismos para desencorajar o surgimento de novas idéias. A academia, utilizando mecanismos brutais de marginalização e exclusão, tais como recusa a emprego, empecilho à publicação, bloqueio a facilidades de pesquisa, difusão de rumores desabonadores e outras tantas estratégias para desencorajar o novo pensar. Há inúmeros exemplos desse tipo de ação. Ver o estudo de Brian Martin: Strategies for dissenting scientists. Journal of Scientific Exploration, v. 12, n. ${ }^{\circ} 4,1998$, p.605-616 e a bibliografia.

D’AMBROSIO, Ubiratan. Transdisciplinaridade. São Paulo: Palas Athena, 1997.

10 Cérebro, mente, pensamento, inteligência, consciência são alguns dos termos usados para se escapar do dualismo corpo/mente. Ver o livro do neurofisiologista William H. Calvin: How brains think. Evolving intelligence, then and now. New York: Basic Books, 1996.
} 
As teorias vão surgindo, vão sendo aceitas ou recusadas, algumas são marginalizadas e outras refutadas. Algumas idéias, que são aceitas por se desviarem pouco das anteriores, se tornam as novas explicações e encontram seu espaço nas universidades. ${ }^{11}$ Outras idéias se desviam dos chamados paradigmas e criam novos paradigmas. ${ }^{12}$ As teorizações sobre a evolução do conhecimento, como as propostas por Kuhn e por Popper, embora antagônicas, defendem, essencialmente, o saber reconhecido pela academia. São refutações e revoluções "amigáveis". Limitam-se a apenas alguns dos fatores que participam da dinâmica do conhecimento. Um filósofo que vai além das limitações de Popper e Kuhn é Michael Polanyi.

Uma categoria fundamental para a análise do comportamento humano é o poder, entendido no sentido amplo da organização sobre a qual se fundam famílias, sociedade e nações. As sociedades humanas modernas são grupos de indivíduos que se comportam em conformidade com normas e valores estabelecidos ao longo da história, resultado de tradições e eventos.

\section{Uma proposta educacional}

Através de sistemas educacionais as sociedades transmitem e inculcam valores que servem de apoio às normas vigentes e aos estilos de comportamento, sobre os quais se apóia a estrutura de poder. Embora para muitos possa parecer um paradoxo, nesses mesmos sistemas educacionais estão embutidos os instrumentos intelectuais que permitem a crítica e a contestação do poder, eventualmente a sua modificação. Juntamente com a transmissão de valores, um sistema educacional tem como meta o desenvolvimento da capacidade de crítica e de contestação. ${ }^{13}$

Há modelos educacionais nos quais não se desenvolvem a capacidade de crítica e de contestação. São baseados na obediência. ${ }^{14}$ Mas o que se nota é que mesmo na transmissão pura e simples de valores, os sistemas educacionais muitas vezes falham. Sempre ficamos chocados quando vemos uma pessoa com um bom nível educacional comportando-se de maneira criticável, algumas vezes até abominável. Porque a educação muitas vezes não influi no seu comportamento? Paradoxalmente, o conhecimento é muitas vezes utilizado para um comportamento ainda mais criticável. ${ }^{15}$

Uma discussão sobre valores não pode escapar de uma reflexão sobre a relação meios-fim. E uma discussão sobre educação tampouco pode escapar dessa relação, que se traduz em afirmações sobre a importância da educação. São valores associados à ação educativa. Espera-se o efeito da ação educativa no comportamento dos indivíduos. O currículo, que é a estratégia da ação educativa, tem como finalidade maior o comportamento dos indivíduos que passam pelo processo. Como o currículo é baseado em conhecimento, em saberes e fazeres, somos levados a uma questão maior: como se relacionam conhecimento e comportamento?

\section{Obediência e ética}

Valores e obediência geralmente se confundem com conhecimento e comportamento.

A obediência é muitas vezes resultado de temor de represálias pela autoridade legítima, e poder é identificado com a sua capacidade de gerar obediência. O temor de represália é ilustrado, num cenário místico, pela punição eterna. É igualmente atemorizante a ameaça de punições físicas, tais como o suplício, a mutilação e a morte. No plano material, essa atemorização se dá pela aplicação de multas e confíscos, e no plano moral, pela censura, confinamento e exclusão.

Mas, a ameaça de represálias geralmente não está no discurso que respalda o poder. A obediência se obtém de maneira mais sutil, sem recurso às ameaças. Muitas vezes se dá através de recompensas, tais como prêmios, distinções

\footnotetext{
Essa é, em essência, a explicação da evolução do conhecimento proposta por Karl Popper.

Essa é outra explicação sobre a evolução do conhecimento, que Thomas Kuhn chamou revolução científica.

Ver D’AMBROSIO, Ubiratan. Educação para uma sociedade em transição. Campinas: Papirus, 1999.

Entendo obediência no comportamento e no conhecimento. Voltarei ao tema mais adiante.

Basta atentar para o fato que um dos crimes mais execráveis, que é o seqüestro para retirada de órgãos, só é possível com a participação de médicos e engenheiros com formação especializada.
} 
e cooptação nos círculos de poder. ${ }^{16}$ Mas, sobretudo, graças à aceitação de um sistema de valores.

No sistema de valores estão incorporadas as atitudes com relação ao outro, que se estendem a grupos de outros identificados por características étnicas, culturais e religiosas. A partir daí se constroem os fundamentalismos, comuns nas sociedades, com os mais variados graus de intensidade.

A percepção de uma ameaça no outro é o ponto de partida para a intolerância do diferente, e a partir daí se parte para a defesa preventiva, que leva inevitavelmente ao ataque.

Outra forma de obediência que resulta de um sistema de valores é assumir como normal a prática de consumismo irresponsável, ganância desmedida e corrupção. São os ingredientes sobre os quais repousa o abuso e posteriormente a agressão ambiental. Muitas vezes nos deparamos com indivíduos que tiveram educação esmerada e adquiriram um bom nível de conhecimento, mas que têm um comportamento agressivo com relação ao ambiente.

Devemos subordinar o sistema de valores a uma ética maior, uma ética que cruze culturas e que coloque prioridade na sustentação do triângulo da vida.

Uma proposta é a ética da diversidade:

\section{RESPEITO pelo outro com todas as suas diferenças;}

2. SOLIDARIEDADE com o outro na satisfação das necessidades de sobrevivência e transcendência;

3. COOPERAC C̃̃O com o outro na preservação do patrimônio natural e cultural comum.

Essa é uma ética que conduz à PAZ INTERIOR, à PAZ SOCIAL e à PAZ AMBIENTAL, e, conseqüentemente, à PAZ MILITAR. Atingir essa PAZ TOTALé o objetivo maior da educação. Como organizar os sistemas educacionais em função desse objetivo maior?

\section{Sobre currículo}

Proponho, como estratégia de uma ação educativa holística, um currículo dinâmico, que foge radicalmente das propostas centradas nos conteúdos, que ainda dominam o currículo atual. Uma profunda re-conceituação de currículo tem sido rejeitada por educadores, em geral.

Mas o que vem a ser currículo? É muito importante que se reconheça que uma aula ou prática educativa é um processo. A esse processo chamamos ação educativa, que como toda ação, resulta de uma estratégia. Para o desempenho da ação educativa o professor vai munido de uma estratégia. Daí a definição que tenho adotado:

Currículo é a estratégia para a ação educativa.

O ponto crítico é a passagem de um modelo de currículo cartesiano, centrado em conteúdos que são escolhidos e organizados previamente à prática educativa, para um modelo de currículo dinâmico, que reflete o momento sócio-cultural e priorizam o entendimento global de fatos e fenômenos. O currículo dinâmico é contextualizado no sentido amplo. O currículo cartesiano, tradicional, responde aos componentes objetivos, conteúdos e métodos. Mas, esses componentes adotam definições obsoletas de objetivos conservadores, respondendo a prioridades da sociedade do momento em que o currículo foi concebido. Conseqüentemente, os conteúdos respondem a esses objetivos obsoletos, que, muito provavelmente, foram importantes em determinado momento histórico. Mas, agora são ancorados em argumentos insustentáveis, transmitidos com métodos que pouco tem a ver com o dia-a-dia dos alunos. Objetivos, conteúdos e métodos são definidos a priori, sem conhecer os alunos e baseados numa estratificação desses alunos em faixas etárias e "níveis de desenvolvimento intelectual" estabelecidos numa situação de laboratório. Esses objetivos, conteúdos e métodos não reconhecem as experiências e as expectativas, que resultam de história individual e comunitariamente coletiva de cada indivíduo. Sintetizando, são conteúdos em geral 
inúteis, transmitidos com uma metodologia falsificada e falsificadora, para atingir objetivos que escapam às perspectivas dos alunos.

O currículo dinâmico parte do reconhecimento que, nas sociedades modernas, as experiências e os interesses dos indivíduos são distintos e, portanto, as classes são heterogêneas, tendo alunos de interesses variados e detentores de uma enorme gama de conhecimentos prévios. Todos esses alunos têm potencial criativo, porém orientados em direções imprevisíveis e com as motivações mais variadas. O currículo, isto é, a estratégia da ação educativa, depende de facilitar a troca de informações, conhecimentos e habilidades entre alunos e professor/alunos, através de uma socialização de esforços em direção a uma tarefa comum. Essa tarefa comum pode ser um projeto, uma discussão, uma reflexão e inúmeras outras modalidades de ação comum, em que cada indivíduo contribui com o que sabe, com o que tem, com o que pode, levando ao máximo o seu empenho na concretização do objetivo comum. Sintetizando, o currículo dinâmico é uma estratégia de ação comum e repousa sobre três etapas que se desenvolvem simultaneamente:

- motivacão, resultado de condições emocionais e da interface passado/futuro;

- elaboracãodenovoconhecimentomediantetroca/ construção/reconstrução de conhecimentos;

- socialização mediante a realização de tarefas comuns.

Esse conceito de currículo serviu de fundamento para um curso de Mestrado que coordenei, a partir de 1975, na Universidade Estadual de Campinas, em convênio com o Ministério de Educação e com a Organização dos Estados Americanos, destinado a preparar liderança para inovações no Ensino de Ciências. ${ }^{17}$

O curso era focalizado na problemática da paz no sentido pluridimensional discutido neste trabalho. Essa foi minha primeira organização das idéias expostas neste trabalho como uma efetiva proposta curricular. Foi a oportunidade de se investigar a possibilidade de uma prática educacional baseada na transdisciplinaridade.

\section{Considerações finais sobre transdisciplinaridade e complexidade}

Outras maneiras de propor a transdisciplinaridade vêm surgindo de muitas áreas do conhecimento. A visão holística, a complexidade ou pensamento complexo, as teorias da consciência, as ciências da mente, a inteligência artificial e inúmeras outras propostas transdisciplinares vêm sendo elaboradas e se tornando conhecidas. Tenho utilizado uma metáfora, que chamo gaiolas epistemológicas, para a transdisciplinaridade, a partir das características do conhecimento disciplinar.

Identifico o conhecimento a partir das disciplinas como "engaiolado" por métodos e resultados bem definidos e rigorosamente organizados para lidar com questões bem específicas. O conhecimento multidisciplinar resulta da justaposição de gaiolas epistemológicas, sem que se passe de uma a outra. Esse é o modelo praticado nas chamadas grades curriculares das escolas: das 08:00 horas às 09:00 horas o aluno/pássaro voa na gaiola "matemática". Toca o sinal, começa outra aula, com outros cadernos e livros, outro professor, e das 09:00 às 10:00 o aluno/pássaro voa na gaiola "geografia", e das 10:00 às 11:00 na gaiola "arte", e, assim, vive seu dia escolar. Sempre engaiolado! Um grande avanço foi o conhecimento interdisciplinar, quando as portas entre as gaiolas são abertas e o aluno/pássaro pode passar de uma gaiola à outra. $\mathrm{O}$ modelo interdisciplinar leva, eventualmente, a um viveiro, na verdade simplesmente uma gaiola maior. A transdisciplinaridade é, metaforicamente, o abandono das grades epistemológicas que limitam o voar/pensar. O grande objetivo da transdisciplinaridade na escola é permitir criatividade plena.

Atransdisciplinaridade tem afinidade a complexidade, ou pensamento complexo. Humberto Mariotti deixa bem claro o que se pretende com o pensamento complexo:

referindo a algo que pode atenuar um modo de viver segundo o qual com enorme freqüência a palavra é separada do real, a justiça se preocupa menos com o sofrimento dos homens do que com a letra da lei, e esta busca verdades que pouco ou nada têm a ver com o cotidiano..$^{18}$ 
E propõe cinco saberes que caracterizam o pensamento complexo e que constituem a essência de uma outra maneira de estar no mundo:

\section{- saber ver;}

- saber esperar;

- saber conversar;

- saber amar;

- saber abraçar.

Esses saberes implicam comportamentos. O abraço se inicia a partir da mão estendida, que é o ponto de partida para o processo de busca da espiritualidade através do encontro com o outro.

Nesses comportamentos está implícito um sistema de valores. Vivenciar esse sistema de valores no cotidiano é o código de conduta que pode redimir o ser humano.
Esse vivenciar implica, muitas vezes, desobediência a ordens e normas de conduta. Cumprir ordens, em conflito com a vontade, não é suficiente como código de conduta. ${ }^{19}$

Alguns indivíduos sentem-se encorajados a essa desobediência numa ação de grupo. São transgressões que, mesmo sujeitas à repressão, deflagram os grandes movimentos sociais. Outros, mesmo sem estar amparados por alguma forma de poder e, às vezes, até contrariando a autoridade, têm a coragem de agir só, fazendo valer o maior dom de ser humano, que é o exercício de sua livre vontade.

A conduta que pode conduzir o ser humano à redenção resulta de se atingir o estado de consciência, quando conhecimento e comportamento estão solidários.

\section{Referências}

CALVIN, William H. How brains think. Evolving intelligence, then and now. New York: Basic Books, 1996.

D’AMBROSIO, Ubiratan. A era da consciência. São Paulo: Editora Fundação Peirópolis, 1997.

. Educação para uma sociedade em transição. Campinas: Papirus, 1999.

(Org.). Ensino de Ciências e Matemática na América Latina. Campinas: UNICAMP/Papirus, 1988.

Cumprir ordens, por si só, não é suficiente como código de conduta ou Obediência e normalidade: uma visão transdisciplinar. In: ESTEVES, Sérgio A. P. Esteves (org.).
O dragão e a borboleta. Sustentabilidade e responsabilidade social nos negócios. São Paulo: Axis Mundi/AMCE, 2000, p.227-242.

MARIOTTI, Humberto. As paixões do ego. Complexidade, política e solidariedade. São Paulo: Palas Athena, 2000, p.324.

MARTIN, Brian. Strategies for dissenting scientists. Journal of Scientific Exploration, v. 12, n. ${ }^{\circ}$, p. 605-615, 1998.

MATURANA, Humberto e VARELA, Francisco. A árvore do conhecimento. As bases biológicas da compreensão humana.

19 D'AMBROSIO, Ubiratan. Cumprir ordens, por si só, não é suficiente como código de conduta ou Obediência e normalidade: uma visão transdisciplinar. In: ESTEVES, Sérgio A. P. (Org.). O dragão e a borboleta. Sustentabilidade e responsabilidade social nos negócios. São Paulo: Axis Mundi/AMCE, 2000, p.227242. 